\title{
Twelve COVID-19 cases preventively vaccinated with MMR: all mild course
}

Désirée Larenas-Linnemann ${ }^{1}$

${ }^{1}$ Hospital Médica Sur

July 7, 2020

Hosted file

Allergy Letter to the Editor text.docx available at https://authorea.com/users/339391/

articles/465609-twelve-covid-19-cases-preventively-vaccinated-with-mmr-all-mild-course 